\title{
ERRATUM
}

G. J. Lee $\cdot$ T. E. Carter Jr $\cdot$ M. R. Villagarcia

Z. Li $\cdot$ X. Zhou $\cdot$ M. O. Gibbs $\cdot$ H. R. Boerma

\section{A major QTL conditioning salt tolerance in S-100 soybean and descendent cultivars}

Published online: 29 January 2005

(C) Springer-Verlag 2005

\section{Theor Appl Genet (2004) 109:1610-1619}

The authors' names appeared in the wrong order on both the online and the printed version. The correct order should be as follows: G. J. Lee, T. E. Carter, Jr., M. R. Villagarcia, Z. Li, X. Zhou, M. O. Gibbs and H. R. Boerma

The online version of the original article can be found at http:// dx.doi.org/10.1007/s00122-004-1783-9

G. J. Lee $\cdot$ H. R. Boerma $(\bowtie)$

Department of Crop and Soil Sciences,

Center for Applied Genetic Technologies,

University of Georgia, Athens, GA 30602, USA

E-mail: rboerma@uga.edu

Tel.: + 1-706-5420927

Fax: + 1-706-5838120

M. R. Villagarcia $\cdot X$. Zhou

Crop Science Department,

North Carolina State University,

Box 7631, Raleigh, NC 27607, USA

T. E. Carter Jr

USDA-ARS, 3127 Ligon St.

Raleigh, NC 27607, USA

Z. $\mathrm{Li}$

Pioneer Hi-Bred, Canola Research Center,

12111 Mississauga Rd., Georgetown,

ON, Canada, L7G 4S7

M. O. Gibbs

Agriculture Extension Agent, P.O. Box 219,

Swan Quarter, NC 27885, USA 